\title{
Schizophrenia, Narcolepsy, and HLA-DR15, DQ6
}

\author{
Alan B. Douglass, James E. Shipley, Richard F. Haines, \\ Robert C. Scholten, Evelyn Dudley, and Andre Tapp
}

A strong association between HLA-DR2, DQ1 and narcolepsy-cataplexy has been known since 1986. In 1990 a subdivision (HLA-DR15, DQ6) was shown to be equally associcted. Narcolepsy symptoms include rapid eye movement (REM)-sleep intrusion hallucinations during the day. Some narcoleptics may br so hallucioutct that they become delusional and receive a diagnosis of schizophrenia. Fifty-six inpatient schizophrenics and 56 normal controls were compared to see if there was an excess of the narcolepsy-associated antigens (NAA) among schizophrenics. Patients had frequency of the NAA 3.89 times higher than controls. After a subset was studied by night $(\mathrm{n}=9)$ and day $(\mathrm{n}=7)$ polysomnography, two patients were found to be true narcoleptics. Their psychosis improved with treatment for narcolepsy. When $N A A(+)$ and $N A A(-)$ schizophrenics were compared, the $N A A(+)$ subgroup had significantly higher Brief Psychiatric Rating Scale (BPRS) scores and more hospitalizations. There were no effects attributable only to gender or race. We conclude that narcolepsy can simulate schizophrenia in some cases, and that even in nonnarcoleptic patients, the HLA-DRI5,DQ6 antigens mark a group of severe schizophrenics that merits further study.

Key Words: Schizophrenia, hallucinations, narcolepsy, cataplexy, HLA-DR antigens, HLA-DQ antigens, REM sleep, epidemiology

\section{Introduction}

Matsuki (et al 1988) demonstrated in Japanese subjects one of the highest associations of HLA antigens with a given disease: HLA-DR2,DQw1 with narcolepsy. This work has since been replicated in most other races. Only in blacks is the association less strong (Neeley et al 1987). Although some DR2-negative cases exist, the "tetrad of narcolepsy"-sleep attacks, cataplexy, hypnagogic hallucinations, and sleep paralysis-very strongly predicts the presence of HLA-DR2,DQ1. Recent work (Honda et al

From the Ann Arbor (RCS, ED, ABD) and Battle Creek VA Medical Centers (ABD, AT); Department of Psychiatry, University of Michigan (ABD, JES); Department of Surgery. Tissue Typing Laboratory. University of Michigan (RFH), Ann Arbor, MI.

Address reprint requests to Dr. Alan Douglass, Psychiatry 116A, VA-Medical Center, 2215 Fuller Rd., Ann Arbor, MI 48105.

Received January 6, 1993; revised August 13, 1993.
1989; Olerup et al 1990) indicates that certainin "splits" or subdivisions of DR2 and DQ1 (namely DR15 and DQ6, hereafter called the "narcolepsy-associated antigens," NAA) are themselves present in nearly $100 \%$ of patients with narcolepsy-cataplexy. This is also true for the haplotype DR15,DQ6,Dw2, although the Dw2 is not a routine antigen in most HLA laboratories. This finding permits greater specificity in the identification of narcolepsy by HLA testing. It should be noted that $10 \%$ or more of normal individuals in the general population will also have the NAA, whereas only about $1 / 1000$ of the general population has narcolepsy. Thus, although the antigens are useful for screening, they are not diagnostic. The modern clinical methods for diagnosing narcolepsy are described below.

The intent of the present article is iv show that this HLA pattern has implications for the diagnosis of schizophrenia as well. The literature on linkage of HLA antigens 
to schizophrenia began in the early 1970s and has been quite controversia!. Many claimed associations have gone unreplicated, due perhaps to racial or diagnostic differences. Because the HLA "Class II" antigens, which include those of particular interest in narcolepsy, were discovered relatively recently, most of the research prior to 1984 was confined to the "Class I" antigens (HLA-A, B, C). Tests for the HLA antigens most specifically predictive of narcolepsy, the NAA, only came into general use in 1990, suggesting the need for a re-evaluation of this area.

There have been several comprehensive reviews of the Class I literature (Goudemand et al 1981; Baron 1986; McGuffin and Sturt 1986). The consensus reached was that HLA testing was not very informative for the diagnosis of schizophrenia. Paranoid schizophrenic patients had a slightly decreased chance of showing the HLA-AI antigen, but an increased chance of A9, A28, B18, B27 (without arthropathy), and $\mathrm{Cw}_{4}$. In hebephrenic schizophrenics, Al and $B 15$ were slightly elevated. If schizophrenia is considered as a whole, HLA-A9 and B5 were increased, whereas Bw35 was decreased. It has been suggested also that HLAAl predicts a good antipsychotic effect of chlorpromazine (Reich et al 1975; Smeraldi et al 1976).

The Class II antigens have been assessed in relatively few studies. A Japanese study (Miyanaga et al 1984) found DRw8 at increased frequency among schizophrenics. An Israeli study (Amar et al 1988) found no significant differences in DR antigens, yet the DR2 rate in schizophrenics in their study was double that of controls. A Scandinavian study (Rudduck et al 1984) found no significant differences in DR. This was also true of a Dutch study (de Jongh et al 1982). None of the above studies examined D or D? antigens. The observed "relative risk" (RR) of schizophrenia versus controls given the presence of any of the above Class II antigens is only about 2 (i.e., doubled risk). This is to be compared to the RR of 70 of ankylosing spondylitis with HLA-B27, and the RR $=750$ of narcolepsy with HLA-DR2/DQ1 (Matsuki et al 1988).

Yet it is possible that the specificity of Class II antigens in narcolepsy could shed light on an old controversy in psychiatry, namely whether some patients with narcolepsy are misdiagnosed as schizophrenic due to their hallucinations. If so, such patients might be regarded as having an organic brain syndrome (narcolepsy), which causes a phenocopy of the schizophrenic syndrome, but through different biological mechanisms.

Clinical reports (Roy 1976; Wilcox 1985) note the existence of a schizophrenia-like illness among narcoleptics. These authors employed a solely clinical definition of narcolepsy. Douglass and colleagues (1991) provided a review of the older literature, and described several new cases of "schizophrenics" with classical narcolepsy. They diagnosed narcolepsy objectively by HLA typing, noctur- nal polysomnography, and the daytime multiple sleep latency test, "MSLT" (Carskadon 1986). Their psychotic patients' hallucinations improved substantially when treated with stimulants, suggesting thai the $\bar{p}$ sychosis may have been due to narcolepsy rather than conventional schizophrenia. This improvement was surprising, as schizophrenic hallucination is usually worsened by stimulants, given that some deficit symptoms may improve (Janowsky and Davis 1976).

We now report the results of a prospective pilot study, the goal of which was to estimate the frequency of narcolepsy in a group of schizophrenic patients. This study was not intended to have a rigorous epidemiological design. Rather, it was a feasibility study to establish whether the earlier findings could be replicated. We also sought any systematic clinical differences between $\mathrm{NAA}(+)$ and NAA( - ) schizophrenics.

\section{Subjects and Methods}

There were 268 psychiatric inpatients with a chart diagnosis of schizophrenia available for study at two VA Hospitals. Exclusion criteria were as follows [number of cases excluded by each criterion shown in square brackets]: any organic brain lesion, history of head trauma, or major medical illness, for example, epilepsy, diabetes mellitus [33]; drug or alcohol abuse in the past year by DSM-III$R$ definition [51]; age greater than 65 years [12]; patient under guardianship or legally incompetent [54]; patient otherwise qualified for inclusion but refused to sign consent [50]; review of ward chart and old chart failed to pass DSM-III-R criteria for cchiznphrenia [1 ?] . A fter excluding the above [212] cases, a schizophrenic group consisting of 56 patients remained. The demographics of age, gender. race, number of hospitalizations, and duration of illness are shown in Table 1 .

A race-matched HLA control group of 56 normal individuals was obtained from the University of Michigan Tissue Typing Laboratory records. These were simply the first 47 white cases and the first 9 black cases found in a retrospective search of organ-donor HLA records, commencing on the date upon which the NAA antigens began to be tested. We did not test controls for the presence or absence of psychiatric illness, which was a weakness of the present design. Family groupings of these persons were known, and the 56 chosen were not related to each other. No formal matching of ethnic or socioeconomic status was done.

The racial composition of the groups was important because HLA antigens associated with narcolepsy are reported to differ in the white and black populations (Neely et al 1986). The statistical design used was to stratify the control and patient groups by race, in case-control fashion. 
Table I. Clinical Variables in NAA( + ) Versus NAA( - ) Patients

\begin{tabular}{lccc}
\hline \multicolumn{1}{c}{ Variable } & NAA( - ), $n=36$ & NAA( +), $n=20$ & Sig. \\
\hline Sex (M : F) & $33: 3$ & $17: 3$ & NS \\
Race (black : white) & $4: 32$ & $5: 15$ & NS \\
Age now & $38.3 \pm 7$ & $40.1 \pm 9$ & NS \\
Years ill & $14.7 \pm 7$ & $14.6 \pm 8$ & NS \\
Age at first admission & $23.4 \pm 5$ & $25.4 \pm 6$ & NS \\
Number of hospitalizations & $15.1 \pm 18$ & $21.8 \pm 38$ & 0.054 \\
SADS-RDC Diagnosis (Schizophren : Schizoaffective) & $14: 22$ & $7: 13$ & NS \\
AP dose (CPZ equiv., mg) & $769 \pm 656$ & $685 \pm 723$ & NS \\
Mood stabilizer augmentation (Y : N) & $3: 30$ & $6: 14$ & 0.066 \\
TCA augmentation (Y : N) & $4: 29$ & $1: 19$ & NS \\
BZD augmentation (Y : N) & $16: 17$ & $6: 14$ & NS \\
Number totally drug-free at BPRS & 3 & 3 & NS \\
\hline
\end{tabular}

Significance values shown are from $x^{2}$ in cornparisons involving binary variables, except where any single cell contained $\leq 5$ subjects, in which case the 2-luiled Fisher Exact Test was employed. For continuous variables, an $F$-test was employed. Those cases "totully drug free" were admitted in a psychotic stute and studied in the sleep lubotatory hefore any antipsychotic drugs were given. Only three patients were first-break psychosis. The remainder had a relapse of their chronic psychosis. These results indicute that the NAN1+) patients hud a more affective, more relapsing illness with a tendency toward a schizo-affective diugnosis. $\mathrm{AP}=$ antipsychotic drugs; $\mathrm{BPRS}=$ Brief Psychiatric Rating Scale; $\mathbf{B Z D}=$ benzodiuzepine drugs; $\mathbf{C P Z}=$ chlorpromazinu; TCA = tricyclic untidepressant or similurly acting drug. Augmentation $=$ drugs used in addition to antipsychutic drigs at any time during the current hospital stay.

All 56 of the patients agreed to a structured diagnostic interview by a trained research nurse. The Schedule for Affective Disorders and Schizophrenia (SADS-L, Endicott and Spitzer 1978) was employed. Those patients having a SADS-RDC (Research Diagnostic Criteria) lifetime diagnosis "schizophrenia" or "schizoaffective" were retained in the study. All schizoaffective patients met the RDC's "mainly schizophrenic" criteria. Most patients were chronically hospitalized and taking antipsychotic drugs at the time of the SADS interview, whercas others were newly admitted and drug-free. Diagnosis and chlorpromazine doseequivalence of antipsychotic medication (Knoben and Anderson 1988) are shown in Table 1. At the time of SADS interview, all patients were also rated on the Brief Psychiatric Rating Scale (BPRS, 18-item version), which was scored 1-7 (Overall and Gorham 1962). Finally, the Sleep Disorders Questionnaire (SDQ, Douglass et al 1990, 1992, 1993) was administered to obtain an assessment of the clinical symptoms of sleep pathology, particularly narcolepsy. The SDQ "NAR" scale provides a percentile score that compares the respondent to a population of narcoleptics diagnosed in a sleep laboratory.

A blood sample was analyzed for HLA Class II antigens using commercial tissue-typing trays at the University of Michigan Tissue Typing Laboratory. The research protocol, as approved, permitted only $\mathrm{NAA}(+)$ patients to be taken off antipsychotic drugs for sleep studies. The rationale was that these were the only patients likely to be narcoleptic, and therefore likely to benefit from the protocol. A more rigorous design would have been to test an equal number of patients with and without the NAA.
All $20 \mathrm{NAA}(+)$ patients were eligible to proceed to the sleep study. For reasons discussed below, only nine completed them. First, their regular antipsychotic dosage was tapered at a rate of $10 \mathrm{mg}$ per week (haloperidol equivalent) to a minimum of $10 \mathrm{mg} / \mathrm{D}$. All medications were then stopped for 2 weeks to enable sleep laboratory testing.

The nocturnal polysomnogram (NPSG) included measurement of electroencephalogram (EEG), electrooculogram (EOG), electromyogram (EMG), electrocardiogram (EKG), oximetry, respiratory airflow, and respiratory effort. The next day, an MSLT was performed to screen for narcolepsy.

Those NAA( +) patients whose sleep laboratory results did not confirm a diagnosis of narcolepsy terminated the study at this point $(n=7)$.

The two NAA( + ) patients whose sleep laboratory results confirmed classical narcolepsy, and one with equivocal findings, received a double-blind trial of the mild central nervous system (CNS) stimulant magnesium pemoline (CYLERT, Abbott Laboratories, North Chicago, Illinois) versus placebo in an A-B design that entailed 1 week of each condition and weekly BPRS ratings. A re-examination of the narcoleptics' medical charts revealed that some years prior to our contact, both had been suspected of having narcolepsy on the basis of clinical symptoms, and had been also psychotic. Although both had been treated briefly and unsuccessfully with amphetamines, their management had been exclusively psychiatric for some years prior to our contact. 


\section{Statistical Tests}

To assess whether theie was a significantly greater frequency of $\mathrm{NAA}(+)$ cases among the 56 patients versus the 56 control subjects, a $\chi^{2}$ test was performed. An a priori hypothesis of an excess of the NAA among schizophrenics was suggested by the results of a previous study (Douglass et al 1991). It is customary to use a formula to inflate the $\chi^{2}$ required for significance (Svejgaard and Ryder 1977) to reduce Type II statistical error in HLA studies involving numerous HLA antigens. This procedure is not required in the case of one or two HLA antigens, which are the subject of an a priori hypothesis. Our $\chi^{2}$ is therefore calculated without the inflation factor. Another $\chi^{2}$ test was performed on all 112 subjects pooled, NAA status versus race, to see if there was an HLA pattern due to race.

Considering only the 56 subjects in the patient group, tests of $2 \times 2$ tables (2-tailed Fisher Exact Test, or $\chi^{2}$ as appropriate) were performed on: NAA status $(+/-)$ versus diagnostic subtype (schizophrenia or schizoaffective); race versus diagnostic subtype; gender versus race; and gender versus diagnostic subtype.

To assess whether NAA( + ) marked an identifiable subsyndrome of schizophrenia, a multivariate analysis of variance (MANOVA, SAS-PC version 6.03) was performed. The categorical variables Race, Sex, and NAA status were used in a 3-way MANOVA design. The analysis was done twice, once on all 56 subjects, and again with the three narcoleptic patients removed from the NAA( + ) group to see if they alone were responsible for any significant differences. Continuous variables in the model included the BPRS score, demographic variables (age, age at first illness, years ill, number of hospitalizations), and six scoring subscales of the SADS ("4. Suicidal ideation and behavior, 7. Delusions and hallucinations, 9. Impaired functioning, 13. Global Assessment Scale, worst period, 14. Extracted Hamilton [depression scale], 23. Social Functioning," Endicott and Spitzer 1978). Before entry into MANOVA, each continuous variable was tested for normality of distribution by the SAS procedure "proc univariate" and Wilk's $W$ Test for normality (Royston 1982). Variables that were obviously skewed, or failed to attain $W \geq 0.85$, were transformed to normalize. $\log _{10}$ transform was used for "number of hospitalizations" and the SADS "Thougint disorder" subscale; logit transform was used for SDQ percentile subscales.

Other categorical variables were gathered to possibly differentiate the $\mathrm{NAA}(+)$ versus the NAA(-) group. These included whether the ward psychiatrist employed an antipsychotic augmentation strategy (antidepressants, benzodiazepines), or mood stabilizers (lithium or carbamazepine). These data were analyzed by two-tailed Fisher
Exact Test, or $\chi^{2}$, as appropriate, depending on whether the smallest cell was $\leq 5$.

The drug trial involved only three patients, so statistical treatment was not attempted.

\section{Results}

In the patient group it was found that $20 / 56$ possessed both NAA. Also, all 20 of these patients were positive for HLADR2,DQ1 although the more specific NAA are the focus of this article. One other patient had HLA-DR15 without DQ6. He was placed in the NAA( - ) group. In the control group, $7 / 56$ had NAA, approximately the rate in the general population (Bauer et al 1984). This difference in observed NAA frequencies was significant $\left(\chi^{2}=8.25\right.$, df $=1, p<0.004)$, and represents an $\mathbf{R R}=3.89(95 \%$ confidence limits: $2.78-5.43$ ).

There was no effect of race alone on the frequency of NAA $\left(\chi^{2}=0.998, \mathrm{df}=1, p=0.32\right)$ among all 112 subjects pooled.

Patients showed no significant difference in the frequency of diagnosis versus NAA status $\left(\chi^{2}=0.83\right.$, df $=1, p=0.77$ ); race versus NAA status (Fisher Exact $p=0.26$; diagnosis versus race $\left(\chi^{2}=0.221, \mathrm{df}=1\right.$, $p=0.54$ ); diagnosis versus gender (Fisher Exact $p=$ 1.00); nor sex versus race (Fisher Exact, $p=0.35$ ) see Table 1. These data were considered for a (multivariate) categorical log-linear model analysis, but the $n$ was not sufficient. They are reported as a series of univariate categorical tests, but the possibility of 'Type-II error must be kept in mind.

Of the $20 \mathrm{NAA}(+)$ patients, nine completed NPSG sleep studies, and only seven completed MSLT studies. One patient had a significant psychotic relapse on withdrawal of medications and so could not complete the protocol. Some accepted the NPSG but would not follow instructions for the MSLT. Table 2 shows the NPSG mean values for the nine patients, and is subdivided into the $6 \mathrm{NAA}+$ ) patients who had a negative MSLT versus the three with a positive MSLT. Considering again the possibility of Type-II error, these results show very little difference in the nocturnal sleep of these NAA( + ) subgroups.

Two of these 20 patients (or $2 / 56=3.8 \%$ of all patients, $95 \%$ confidence limits: $0.0-11.4 \%$ ) proved to have the clinical syndrome of classical narcolepsy (cataplexy witnessed by us, sleep attacks in meetings, sleep paralysis, hypnagogic hallucinations). In the MSLT studies (Table 3), they both had four or more sleep-onset REM (SOREM) naps and pathologically short mean sleep latencies (MSL) such that the clinical diagnosis of narcolepsy was confirmed objectively. A third patient had three SOREM naps 
Table 2. Nocturnal Sleep Results of NAA( + ) Patients

\begin{tabular}{|c|c|c|c|c|c|c|}
\hline $\begin{array}{l}\text { Nocturnal sleep } \\
\text { measure }\end{array}$ & $\begin{array}{c}\text { Patient l } \\
\text { (narcolepsy, NAA +) }\end{array}$ & $\begin{array}{c}\text { Patient } 2 \\
\text { (narcolepsy, NAA +) }\end{array}$ & $\begin{array}{c}\text { Patient } 3 \\
\text { (equivocal, NAA +) }\end{array}$ & $\begin{array}{c}\text { Mean of } \\
\text { Patients 1-3 }\end{array}$ & $\begin{array}{c}6 \mathrm{NAA}(+), \\
\text { Nonnarcoleptic cases } \\
(\text { mean } \pm \text { SD) }\end{array}$ & Significance \\
\hline TRP & 448 & 329 & 372 & 383 & $360 \pm 42$ & $0.61 \mathrm{NS}$ \\
\hline SL & 15 & 6 & 61 & 27.3 & $92.7 \pm 58$ & $0.07 \mathrm{NS}$ \\
\hline ALT2 & 29 & 20 & 1 & 16.7 & $20.5 \pm 24$ & $0.89 \mathrm{NS}$ \\
\hline \# Wakes & 16 & 8 & 5 & 9.7 & $3.2 \pm 3.5$ & 0.04 \\
\hline WASO & 135 & 103 & 6 & 81.3 & $30.5 \pm 52$ & $0.30 \mathrm{NS}$ \\
\hline TSA & 297 & 220 & 305 & 274 & $230 \pm 78$ & 0.44 NS \\
\hline SE (tsa/trp) & 66.3 & 66.9 & 82.0 & 71.7 & $64.4 \pm 22$ & $0.89 \mathrm{NS}$ \\
\hline \% STAGE 1 & 66.7 & 47.3 & 40.3 & 51.3 & $38.1 \pm 25$ & $0.44 \mathrm{NS}$ \\
\hline \% STAGE 2 & 23.6 & 41.8 & 41.0 & 35.5 & $47.0 \pm 12$ & 0.30 NS \\
\hline \% REM & 9.4 & 10.9 & 18.7 & 13.0 & $22.6 \pm 6.5$ & 0.051 \\
\hline $\begin{array}{l}\text { \% REM } \\
\text { periods }\end{array}$ & 2 & 4 & 3 & 3 & $2.6 \pm 0.8$ & $0.52 \mathrm{NS}$ \\
\hline RL & 302 & 1.0 & 71 & 124.7 & $41.6 \pm 102$ & 0.55 NS \\
\hline RLMA & 198 & 1.0 & 70 & 89.6 & $40.0 \pm 61$ & $0.37 \mathrm{NS}$ \\
\hline RT & 28 & 24 & 57 & 36.3 & $58.6 \pm 20$ & $0.10 \mathrm{NS}$ \\
\hline RA (units) & 74 & 30 & 43 & 49 & $68.2 \pm 19$ & $0.18 \mathrm{NS}$ \\
\hline RD (RA/RT) & 2.6 & 1.2 & 0.7 & 1.5 & $1.40 \pm 0.75$ & $0.86 \mathrm{NS}$ \\
\hline
\end{tabular}

Detailed results of Nocturnal Polysomnography (NPSG) on the three patients who had both HLA.DR15,DQ6 (i.e.: NAA +), and clinical symptoms of narcolepsy. Putients 1 and 2 had the full tetrad with witnessed catuplexy. Patient 3 was delusional, had visual hallucinations, no cataplexy, and an equivocal MSLT. A further 6 NAA + ) patients withoul clinical or MSLT evidence of narcolepsy are shown for comparison. Because of nonGaussian distributions and small $n$, variables were compared by the nonparametric Kruskal-Wallis Test. Groups: the 3 NAA + ) versus the $6 \mathrm{NAA}(-)$ cases. See text for discussion of these results as they affect the validity of the MSLT.

TRP = total recording period; $S L=$ sleep latency (number of minutes from lights-out until $90 \mathrm{sec}$ of stage $1 ;$ or $30 \mathrm{sec}$ of slage 2 sleep); ALT2 = min awake in last $2 \mathrm{hr}$ of recording; \#WAKES = number of wakes of $2 \mathrm{~min}$ or greater during the night; WASO $=$ minutes of wake after sleep onset; TSA $=$ time spent asleep (min); SE $=$ sleep efficiency: \%Stage $1 \ldots \%$ Stage $2=$ light sleep expressed as a percentage of TSA; \%REM = min Rapid Eye Movement sleep as percentage of TSA RL = min from sleep onset to first observed REM sleep epoch; RLMA = "RL minus awake"; $R T=$ REM time in min; RA $=$ REM activity (Kupfer units); RD = REM density

Table 3. Daytime MSLT Results

\begin{tabular}{lllll}
\hline \multicolumn{1}{c}{ Variable } & Patient 1 & Patient 2 & Paticnt 3 & $\begin{array}{c}\text { All other } \\
\text { NAA(+) } \\
\text { patients, } \\
n=4\end{array}$ \\
\hline Nap \# 1: SL (RL) & $1.0(1.5)$ & $3.5(3.5)$ & $17(16)$ & \\
Nap \#2: SL (RL) & $3.5(4.0)$ & $3.0(2.0)$ & $17(12)$ & \\
Nap \#3: SL (RL) & $1.0(4.0)$ & $2.0(7.0)$ & $-(--)$ & \\
Nap \#4: SL (RL) & $2.0(4.0)$ & $2.5(0.5)$ & $10(10)$ & \\
Nap \#S: SL (RL) & $3.0(7.0)$ & $-(-)$ & $-(-)$ & \\
MSL (MRL) & $2.1(4.1)$ & $2.8(3.3)$ & $14.6(12.6)$ & $21.0(-)$ \\
\#SOREMs & $5 / 5$ & $4 / 4$ & $3 / 5$ & $0 / 5$ \\
\hline
\end{tabular}

Results of Multiple Sleep Latency Test (MSLT), done the day after the NPSG of Table 1. Standard 5 nap protocol. All latencies are shown as minutes. SL $=$ Sleep Lutency: $\mathrm{RL}=\mathrm{REM}$ sleep latency following $\mathrm{SL} ; \mathrm{MSL}$ = mean sleep latency in the naps; MRL = mean RLiM sleep latency in naps; SOREMs $=$ number of sleep onset REM periods. Results for patients 1 and 2 suggest classical narcolepsy. Patient 3 has SOREM naps as do the narcoleptics, but a normal MSL, which is atypical for narcolepsy.

but a near-normal MSL and no witnessed cataplexy despite giving a history of partial cataplexy, therefore he was given a diagnosis of "equivocal narcolepsy." All three were men, and carried a SADS-RDC lifetime diagnosis of "schizoaffective, mainly schizophrenic type" and a DSM-III-R diagnosis of paranoid schizophrenia.
Obstructive sleep apnea (OSA) was also present in patients \#1 and \#2. Results for patient \#1: number of apneas $=106$, hypopneas $=82$, apnea-hypopnea index $=38$, lowest arterial oxygen saturation $\left(\mathrm{SaO}_{2}\right)$ desaturation $=$ $70 \%$, mean duration of events $=20 \mathrm{sec}$. Results for patient \#2: number of apneas $=116$, apnea-hypopnea index $=$ 61 , lowest $\mathrm{SaO}_{2}$ desaturation $72 \%$, mean duration of events $=15 \mathrm{sec}$. These patients were offered continuous positive airway pressure (CPAP) treatment for apnea before their MSLT study. Patient \#1 refused for delusional reasons, whereas patient \#2 accepted. Thus \#1's MSLT shows the effect of apnea plus narcolepsy, whereas \#2's shows only the effect of narcolepsy. Two years later, \#1 accepted CPAP in addition to narcolepsy treatment, and his clinical condition improved further.

The BPRS scores of these three patients during the drugfree baseline, placebo, and pemoline conditions were as follows: \# 1-68, nil, 36; \#2-64, 67, 44; \#3-29, 37, 32, Pemoline therefore caused a substantial reduction in BPRS score in the 2 classical narcoleptics, but not in the equivocal case \#3.

The MANOVA results were significant for the NAA dimension, but not for gender or race (Table 4). Subsequent one-way ANOVAs showed significant differences in the pattern of clinical variables between $\mathrm{NAA}(+)$ and 
Table 4. One Way ANOVAs following MANOVA

\begin{tabular}{lcccc}
\hline \multicolumn{1}{c}{ Variable } & $\begin{array}{c}\text { NAA(-) } \\
n=36\end{array}$ & $\begin{array}{c}\text { NAA(+) } \\
n=20\end{array}$ & $\begin{array}{c}\text { Significance } \\
(n=56)\end{array}$ & $\begin{array}{c}\text { Significance } \\
(n=53)^{*}\end{array}$ \\
\hline BPRS total score & $32.8 \pm 9.7$ & $46.9 \pm 15$ & 0.0008 & 0.0024 \\
Suicidality (SADS scale 4) & $2.72 \pm 2.4$ & $4.20 \pm 3.8$ & 0.02 & 0.016 \\
Hallucination/delusion (SADS 7) & $38.2 \pm 8.5$ & $36.4 \pm 9.8$ & NS & NS \\
Inipaired functioning (SADS 9) & $5.53 \pm 2.2$ & $6.67 \pm 2.2$ & 0.06 & 0.045 \\
GAS at worst (SADS 13) & $33.7 \pm 6.3$ & $29.13 \pm 12$ & NS & NS \\
Derived Hamilton (SADS 14) & $17.2 \pm 7.4$ & $17.53 \pm 8.7$ & NS & NS \\
Social Function (SADS 23) & $19.0 \pm 4.3$ & $19.8 \pm 4.0$ & NS & NS \\
\hline
\end{tabular}

A three-way multivariate unalysis of variance (MANOVA. NAA $\times$ Race $\times$ gender) was performed on 10 variables which inspection suggested would demonstrate differences between $\mathrm{NAA}(+)$ and $\mathrm{NAA}(-)$ groups. These included all the variables in Table 4, plus "CPZ equivalent dose," "Years ill." and "Number of hospitalizations" from Table 1. MANOVA was significant, but only for the dimension "NAA Sturus," $(F=2.49 . \mathrm{df}=11 / 27 . p=0.026)$. Dimensions "Sex" and "Race" were not significant. One-way ANOVAs were then performed on the variubles underlying the NAA dimension of the MANOVA. only, to identify the source of significance. This table shows all subjects $(n=56)$. When the three narcoleptic subjects were removed from the NAAl + ) group $(" n=53)$, the significance puttern remained the same (MANOVA for NAA: $F=3.35, p=0.0047)$, indicating that these tindings also apply to the $\mathrm{NA \Lambda}+$ ) group as a whole.

NAA( - ) patient subgroups. When the three narcoleptics v'ere removed from the data and the statistic done again, the pattern of significance was not altered (Table 4). These results suggest that the NAA(+) group as a whole, not just the diagnosed narcoleptics, had a more symptomatic form of schizophrenia as measured by the BPRS. Comparing Table 1 with Table 4 suggests that the NAA( +) group had a more affective form of schizophrenia with higher numbers of hospitalizations, greater use of mood stabilizers to augment their antipsychotic drugs, more suicide attempts, and more impaired functioning. Although this would seem to suggest a schizoaffective diagnosis, the frequency of SADS-RDC diagnoses did not differ significantly (Table 1).

The SDQ "NAR" scales of patients \#I-\#3 were 99 , 98, 72 percentile, respectively. This indicates that their responses resemble those of the most severe nonpsychotic narcoleptics in the SDQ reference group. With these three patients removed, the NAA + +) group percentile mean on NAR scale was $38.1 \pm 31$, and the NAA( -$)$ group 33.5 \pm 33 (NS by $t$-test).

Patients \# I-3 have been treated in follow-up for 2 years with lithium carbonate and pemoline but no antipsychotics have been required. Symptoms of auditory, visual, and tactile hallucinations improved within a week. Those hallucinations remaining were obviously hypnagogic, occurring when the patient missed medication or was overtired. Interestingly, patients no longer elaborated them into delusional themes. Delusic nal paranoid ideas and disorganized thought also disappeared, but over several months. On their medications for narcolepsy and mood stabilization, (and CPAP for sleep apnea in patients \#1 and 2), none of the three would currently meet criteria for a diagnosis of schizophrenia.

\section{Discussion}

These results suggest that classical narcolepsy may have been involved in the etiology of the psychosis of two patients $(3.6 \%)$ in our sample of patients hospitalized for schizophrenia. In addition, there was one equivocal case of narcolepsy found who had REM intrusion but not objective excessive sleepiness on MSLT. The psychotic symptoms in these three patients resolved with stimulant treatment, whereas previous treatment with antipsychotic drugs had been ineffective.

A positive MSLT is central to the diagnosis of narcolepsy. Was there sufficient nocturnal REM sleep to validate these MSLTs? The nocturnal sleep of the patients with narcoleptic MSLTs, although poor in quality and duration, was not significantly different from the other schizophrenic patients who had normal MSLTs (Table 2), suggesting that these were not false positives. None of the NPSG REM variables was significantly different.

Although some narcolepsy patients have a short nocturnal REM-onset latency, as do many depressed patients (Kupfer 1976), this has only been reported recently in schizophrenics (Kumar et al 1985; Zarcone et al 1987; Tandon et al 1992). The reported latencies are as short as those commonly reported for depression. Other schizophrenics have a nocturnal REM latency no different from that of normals (Kempenaers et al 1988; Reich et al 1975). It will be interesting to see whether some "schizophrenics" with short nocturnal REM latencies prove to have daytime MSLT REM latencies which are so short as to meet the criteria for narcolepsy. If so, they may be not schizophrenic at all, but narcoleptic, as were some patients in this study. Such schizophrenic patients could be screened for narcolepsy by means of the NAA, but these have the disadvantage of costing about $\$ 300$ per patient. One ad- 
vantage is that they can be done while the patient is still on antipsychotic medications, unlike a sleep study. In the absence of HLA-DR 15,DQ6 a patient is extremely unlikely to have narcolepsy as a contributing cause of psychosis.

The face validity of the SDQ "NAR" scale to screen for narcolepsy among schizophrenics receives strong support in these three cases. More support for the narcoleptic diagnosis comes from our observation of gross hypnagogic hallucinations during naps in two of the narcoleptic patients. Both would fall asleep in group therapy, then partially awake in a confused state in which they were talking out of context, apparently to their hypnagogic hallucinations-very "schizophreric" when seen on a ward of schizophrenics, yet also quite common among nonpsychotic narcoleptics in the waiting rooms of sleep disorder clinics! Also, both had "falling attacks" (cataplexy) during times of sudden emotion such as anger, laughter, or surprise.

A major limitation of this study is that we did not obtain sleep studies in the NAA(-) patients. This needs to be done in future to control fully for the possibility that a "narcoleptic" MSLT is present in some psychotic patients who are taken off antipsychotics for 2 weeks.

Obstructive sleep apnea was present in two of our narcoleptics. It may be that this is a coincidental finding. Alternatively, it may be that apnea is partially responsible, in concert with narcolepsy, for the induction of an organic brain syndrome predisposing to visual hallucinosis. In future cases, there should be a full reassessment of the psychiatric and polysomnographic status after resolution of the apnea but before the narcolepsy is treated with stimulants.

The significant mean BPRS elevation in the NAA(+) patients versus NAA( - ) patients was unexpected. Although the possibility of Type Il error must be considered, it seems that there was a tendency for the NAA to be associated with greater symptom severity: greater history of suicidal intent, suicidal behavior, and more hospital admissions. This also suggests an affectively laden, re-

\section{References}

Amar A. Zohar M, Tiwari J, Brautbar C (1988): HLA and schizophrenia in Israel. Isr J Med Sci 24:28-31.

Baron M (1986): Genetics of schizophrenia: II. Vulnerability traits and gene markers. Biol Psychiatry 21:1189-1211.

Bauer MP ei al (1984): Population analysis on the basis of deduced haplotypes from random families. In Albert ED, Bauer MP, and Mayr WR (eds), Histocompatibility Testing 1984. New York: Springer-Verlag.

Carskadon MA, Dement WC, Mitler MM, Roth T, Westbrook PR, Keenan S (1986): Guidelines for the multiple sleep la- lapsing illness. Alternatively, these findings could mean that members of the NAA + ) group were for some reason less responsive to their particular antipsychotic drugs over the years. There were proportionally more SADS-RDC schizoaffectives among the NAA( + ) group, although this difference was not statistically significant. Further support for a connection between NAA( + ) status and a schizoaffective clinical picture is that the ward psychiatrists chose to augment their treatment of these patients with mood stabilizing medication at much higher rates than they did with NAA(-) schizophrenics, and that difference approached significance. They also used less tricyclic antidepressants (TCA) and benzodiazepine (BZD) medications with the NAA( + ) group.

All of these findings must be regarded as preliminary until they can be replicated in a larger sample.

In summary, this study suggests that narcolepsy and sleep apnea can be occult diagnoses in some patients who appear at first to have schizoaffective disorder with prominent psychotic symptoms, unresponsive to the sommon antipsychotic medications. The follow-up of our three patients treated with pemoline and lithium has now passed 2 years without a psychotic relapse, which represents a major improvement in their condition. The benefit from lithium is interesting. It may suggest that the patients had an underlying diagnosis of bipolar disorder that was obscured by the cognitive and hallucinatory symptoms of sleep apnea and narcolepsy, respectively. In this scenario, persistent abnormalities of thought plus persistent hallucinations caused by the sleep disorders may have resulted in a diagnosis of RDC schizoaffective schizophrenia by mistake.

Supported by NIH grant No. MOI-RR00042 (Kughn Clinical Research Center, University of Michigan Medical Center), and by infrastructure provided by Dr. Spencer Falcon via the Battle Creek Initiative Program of the Dept. of Veterans Affairs (Central Region). We thank Angela Messina for her invaluable technical assistance with the data analysis.

An earlier version of this paper was read at the Annual Meeting of the Society of Biological Psychiatry. New Orleans, LA.. May 1991.

tency test (MSLT): A standard measure of sleepiness. Sleep 9:519-524.

de Jongh BM, Verhoeven WM, van Ree JM, de Wied D, van Rood JJ (1982): HLA and the response to treatment with gamma-type endorphins in schizophrenia. I Immunogenet 9:381-388.

Douglass AB, Hays P (1987): Three simultaneous major sleep disorders. Can J Psychiatry 32:57-60.

Douglass AB, Bornstein RA, Nino-Murcia G, Keenan S, Miles L, Zarcone VP Jr., Guilleminault C, Dement WC, Abelseth 
D (1990): Item test-retest reliability of the Sleep Disorders Questionnaire (SDQ). Sleep Res 19:215.

Douglass AB, Hays P, Pazderka F, Russell JM (1991): Florid refractory schizopirrenias that tum out to be treatable variants of HLA-associated narcolepsy. J Nerv Ment Dis 179:12-17.

Douglass AB, Shipley JE, Nino-Murcia G, Keenan S, Miles L, Guilleminault C, Zarcone VP Jr., Dement WC (1992): Validation of the "PSYCH" scale of the Sleep Disorders Questionnaire (SDQ). Sleep Res 21:150.

Douglass AB. Bornstein R, Nino-Murcia G, et al (1993): The Sleep Disorders Questionnaire l: creation and multivariate structure of SDQ. Sleep (in press).

Endicott J, Spitzer RL (1978): A diagnostic interview: The Schedule for Affective Disorders and Schizophrenia. Arch Gen Psychiatry 35:837-845.

Goudemand M, Goudemand J, Parquet PJ, Fontan M (1981): Psychoses schizophreniques et antigenes HLA [Schizophrenic psychoses and HLA antigens. Personal data and review of the literature|. Encephale 7:609-622.

Honda Y, Matsuki K. Juji T. Inoko H (1989): Recent progress in HLA studies and a genetic model for the development of narcolepsy. In Burton SA, Dement WC, Ristanovic RK (eds), Narcolepsy Third International Symposium, Selected Symposium Proceedings. Oak Park, IL: Matrix Communications, pp 27-33.

Janowsky DS, Davis JM (1976): Methylphenidate, dextroamphetamine, and levamfetamine, effects on schizophrenic symptoms. Arch Gen Psychiairy 33:304-308.

Kempenaers C, Kerkhofs M, Linkowski P, Mendlewicz J (1988): Sleep EEG variables in young schizophrenic and depressive patients. Biol Psychiatry 24:828-833.

Knoben JE, Anderson PO (1988): Handbook of Clinical Drug Data 6th ed. Hamilton IL: Drug Intelligence Publications Inc., pp 577-579.

Kumar A. Greden J. Grunhaus L, Eiser A (1985): Sleep onset REM periods in paranoid schizophrenia. Biol Psychiatry 20:815-816.

Kupfer DJ (1976): REM latency: A psychobiologic marker for primary depressive disease. Biol Psychiatry 11:159-174.

Matsuki K. Honda Y, Sataka M, Juji T (1988): HLA in nar- colepsy in Japan. In Honda Y, and Juji T (eds), HLA and Narcolepsy. New York: Springer Verlag.

McGuffin P, Sturt E (1986): Genetic markers in schizophrenia. Hum Hered 36:65-88.

Miyanaga K, Machiyama Y, Juji T (1984): Schizophrenic disorders and the HLA-DR antigens. Biol Psychiatry 19:121129.

Neely S, Rosenberg R, Spire I-P, Antel J, Amason BG (1987): HLA antigens in narcolepsy. Neurology 32:1858-1860.

Olerup O, Schaffer M, Hillert J, Sachs C (1990): The narcolepsyassociated DR 15, DQ6, Dw2 haplotype has no unique HLA$D Q \alpha$ or $-D Q \beta$ restriction fragments and does not extend to the HLA-DP subregion. Immunogenetics 32:41-44.

Overall JE, Gorham DR (1962): The brief psychiatric rating scale. Psychol Rep 10:799-812.

Reich L, Weiss BL, Coble P, McPartland R, Kupfer DJ (1975): Sleep disturbance in schizophrenia, a revisit. Arch Gen Psychiatry 32:51-55.

Roy A (1976): Psychiatric aspects of narcolepsy. Br J Psychiatry 128:562-565.

Royston JP (1982): An extension of Shapiro and Wilk's W Test for normality to large samples. Appl Statist 31:1 15-124.

Rudduck C, Franzen G, Low B, Rorsman B (1984): HLA antigens and clinical subgroups of schizophnenia. Hum Hered 34:18-26.

Smeraldi E, Bellodi L, Sacchetti E, Cazzullo CL (1976): The HLA system and the clinical response to treatment with chlorpromazine. Br J Psychiary 129:486-489.

Svejgaard A, Ryder LP (1977): Association between HLA and disease, notes on methodology and a report from the HLA and Disease Registry. In Dausset J, Svejgaard A (eds), HLA and Disease, Copenhagen: Munksgaard, pp 46-53.

Tandon R. Shipley JE, Taylor S, et al (1992): Electroencephalographic sleep abnormalities in schizophrenia. Arch Gen Psychiatry 49:185-194.

Wilcox J (1985): Psychopathology and narcolepsy. Neuropsychobiology 14:170-172.

Zarcone VP, Benson KL, Berger PA (1987): Abnormal rapid eye movement latencies in schizophrenia. Arch Gen Psychiatry 44:45-48. 